\title{
A Research on the Mediating Role of Flow Experience between Involvement and Satisfaction-Focus on Leisure Satisfaction for University Students
}

\author{
Heejung Lee, Janghyun Kim, Ilhyun Bae
}

\begin{abstract}
This study examines how 'flow experience' plays role between leisure involvement and leisure satisfaction. We will focus on mediating role of 'flow experience' by using University student respondents. The study of results are as follows.

First, situational/enduring involvement has a significant relationship with flow experience. Second, higher levels of flow experience lead to high levels of emotional /psychological /social satisfaction in leisure. Finally, we find the effects of situational/ enduring involvement on satisfaction were mediated by flow experience. The results of this study provide significant implication to various area.
\end{abstract}

Keywords :Situational Involvement, Enduring Involvement, Flow experience

\section{INTRODUCTION}

$\mathrm{G}$ reat attention has been shown to the question of 'flow experience' in the various field. Especially, 'flow experience' in computer game and sports is an important research topic that has recently attracted the attention of researchers. Curiously, despite the rise of 'flow experience' as an academic discipline, few have attempted address this factor in leisure activity. So, this study examines how 'flow experience' plays role between leisure involvement and leisure satisfaction. We will focus on mediating role of 'flow experience' by using University student respondents. The results of this research will provide significant implications to various area.

\section{LITERATURE}

Leisure is activity - apart from the obligations of work, family, and society - to which the individual turns at will, for either relaxation, diversion, or broadening his knowledge and his spontaneous social participation, the free exercise of his creative capacity [1]. Leisure does not necessary to be with social expectations, or survival [2]. Rather, leisure should be accompanied by emotional and psychological rewarding as an individual spends time for his/her self-development [3, 4, 5].

Revised Manuscript Received on July 22, 2019.

Heejung Lee, Department of Business Convergence, CHA University, 11160, Republic of Korea, Email: hjlee@ cha.ac.kr

Janghyun Kim, Department of Business Administration, Kunsan National University, 54150, Republic of Korea, Email: jkim@kunsan.ac.kr

*Ilhyun Bae , College of Global Business Administration, Hyupsung University, 18330, Republic of Korea,Email:baeih102@naver.com
One can be satisfied if he/she has satisfied with its output, such as having chance to self-development or being healthy. Leisure satisfaction is a subjective feeling while joining in eisure activities. Leisure is known as an important factor in pursuing well-being as well as improving the quality of life. Leisure should be understood the meanings of three perspectives; activity, psychology, and time. The satisfaction of leisure can be achieved through multi-dimensional components including positive emotional, educational, social, relaxation, physiological, social and physiological factors [5]. For example, social satisfaction can be achieved by interacting or communicating with other people while doing leisure activities. Emotional satisfaction means satisfying positive emotions and lowering the feeling of anxiety. Meanwhile, the concept of leisure boredom was suggested that can be defined as a negative mood or state of mind that shows a mi-match between optimal experiences and actual experiences that individuals can achieve [6]. One can experience leisure boredom if they fail to choose leisure activities suitable for themselves. Leisure boredom refers to negative feelings about personal leisure experience.

The construct of involvement has been widely studied in the leisure and tourism research. Most studies have paid attention into the impacts of involvement on individuals' attitudes and behaviors in the leisure context. According to Kapferer and Laurent, underlying components of involvement include interest, pleasure, perceived probability, consequence of risk, and self-expression [7]. Zaichkowsky's Personal Involvement Inventory has been also employed often in the previous studies [8]. In the leisure context, McIntyre and Pigram suggested three underlying components; attraction (importance of a specific activity), self-expression (symbolic of a specific activity), and centrality of lifestyle [9]. Following their research, leisure involvement was measured using the three component: attraction, self-expression and centrality of a lifestyle [10, 11]. Attraction refers to the pleasure that individual drives from participation in the specific activity; centrality is the significance of the activity; and self-expression refers to the impression of the self that individuals want to communicate with others by participation. Leisure involvement was argued as the factor that can reduce one's stress level [12] and also reduce one's loneliness [13]. 
The leisure involvement was found to play a part as $t$ mediator between leisure motivation and psychological satisfaction [14].

Research done by Havitz and Mannell investigated the role of involvement in participants' satisfaction and flow experience [15]. The leisure involvement can be divided into two different components; enduring involvement and situational involvement. The enduring involvement is quite effective predictor in the leisure settings [16] and also stable compared to situational involvement changing slowly over time [17, 18]. According to Havitz and Mannell, participants with higher levels of enduring involvement are more likely to experience higher levels of flow [15]. Situational involvement was also mediating between enduring involvement and flow experience.

Flow is the experience of total devotion of attention on what one is doing [19]. The original work done by Csikszentmihalyi identified the concept of flow by conducting interviews with people about what they felt when an activity is going well [19]. While one experiences flow, one is no longer thinking about him/herself being separate from the immediate activity. While one is in flow, they have clear goals and tend to have immediate feedback to one's actions [20]. Individuals engage in hobby, such as dancing, doing artwork etc, which can be called 'flow experience'. In a flow state, an individual does not count time, and the activity is guided by an inner logic not being separated from the self anymore, which lead to a loss of self-consciousness. Therefore, flow explains why individuals are highly committed to tasks even when lacking external rewards [20]. Furthermore, flow is often related to high performance [21] as it positive emotions like joy or happiness.

Once an individual is fully engaged, a feeling of control can be achieved. Flow condition was also identified as one of the factors that are related to one's happiness in everyday life [22]. In the study of $\mathrm{Wu} \&$ Liang, flow experience increases the level of leisure satisfaction [23]. Heo, Lee, McCormick \& Pedersen also empirically showed that flow experience enhances happiness [24]. Research on flow experience has suggested that there are some major facilitator of flow experience; perceived ability, intrinsic motivation to experience stimulation, and anxiety [25]. Researchers have identified the measurement scale for flow experience. For example, to measure the flow experience, Jackson \& Marsh developed the Dimensional Flow Scale that has nine underlying components of flow [26]. Each component has four items to measure this concept. Later, Jackson, Martin \& Eklund suggested the simple version that has nine-item to measure the flow, which is much shorter than original work having only one item for each of nine component of flow [27].

During the leisure activities, individuals' flow experience is known to be influenced by their involvement and internal motivation $[15,28]$. In doing leisure, if individuals are highly involved, they are highly likely to experience flow. Individuals with higher leisure involvement are likely to try to express themselves, enjoying pleasure moment and obtaining the best experience. The flow experience is not only expected to influence the level of emotional satisfaction, but also physiological and social satisfaction. When people experiencing flow during leisure, they are completely immersed in their activity and are likely to be satisfied about their leisure activity. Although previous studies argued the importance of flow experience, empirical evidence is lacking. Following the previous studies, this study suggests the conceptual model that flow experience mediates the leisure involvement and leisure satisfaction.

H1 higher levels of situation involvement are positively associated with a higher flow experience.

$\mathrm{H} 2$ higher levels of enduring involvement are positively associated with a higher flow experience.

H3 Higher levels of flow experience lead to high levels of emotional satisfaction in leisure.

H4 Higher levels of leisure flow experience lead to high levels of physiological satisfaction in leisure.

H5 Higher levels of leisure flow experience lead to high levels of social satisfaction in leisure.

\section{ANALYSIS}

The purpose of this study is to investigate the effect of situational involvement and enduring involvement on leisure satisfaction of university students. And we investigated whether this relationship is mediated by flow experience. In addition, this study divides the satisfaction of leisure into physiological satisfaction, social satisfaction, and emotional satisfaction, and confirm causality.

Following previous studies, 6 components of measurement items were employed as follows. The 'situational involvement' was measured by asking the level of participation in leisure activities (1: Never, 2: Monthly 1 to 2 times, 3: Monthly 3 to 4 times, 4: Monthly 5 to 6 times, 5: More than 7 times a month, 6: Almost every day) for each leisure activity. Various kinds of leisure activities were asked including sports/health, hobbies/culture, viewing/ appreciation, social/social activities, tourism/ travel, and play/ recreation areas. The mean value of each item was calculated and applied to the 'situational involvement' component. To measure 'enduring involvement', five items were employed based on previous studies $[15,28]$. Example items include "my leisure activities have special meaning for me' and 'I cannot imagine my life without leisure activities". The component of 'flow experience' was measured by employing nine items [26]. For example, "I feel very happy during my leisure activities", "Experiencing leisure activities makes me feel like I am in another world". Leisure satisfaction was measured by employing three components based on LSS (Leisure Satisfaction Scale) developed by Beard and Ragheb [3]. Four items were used to measure 'emotional satisfaction' and 'physiological satisfaction' each. Five items were used to measure social satisfaction. All items were measured using seven-point Likert scale. Example items include 'my leisure activities keep me close with other people' (social satisfaction), 'my leisure activities can improve my physical strength' (physical satisfaction) and 'my leisure activities make me feel fulfilled' (physiological satisfaction).

To achieve study objectives, a total of 390 college students were collected and analyzed. The respondents' grades were 161 in the first year, 127 in the second, 82 in the third, and 12 in the fourth grade. 
The gender of the respondents was 156 males and 234 females. Partial least squares analysis, using the Smart PLS 3.0 software, was applied to analyze the proposed causality.

First, internal consistency reliability was confirmed for each variable used in this study. Cronbach's alpha, rho_A, and Composite Reliability met the criterion. Next, validity was confirmed. The average variance extracted was greater than 0.5 for all variables. Convergent validity was confirmed. Discriminant validity was confirmed by satisfying the criterion for all values of cross loading, Fornell and Larcker criterion, and Heterotrait-Monotrait ratio. Finally, the correlation value appears in a positive direction, indicating that nomological validity exists.

After confirming credibility and validity, hypothesis was examined. For hypothesis examination, Smart PLS 3.0 was used. Analysis result for each path was all statistically significant as shown in Figure 1. All paths among the constructs were significant. Furthermore, the effects of situational/enduring involvement on satisfaction were mediated by flow experience.

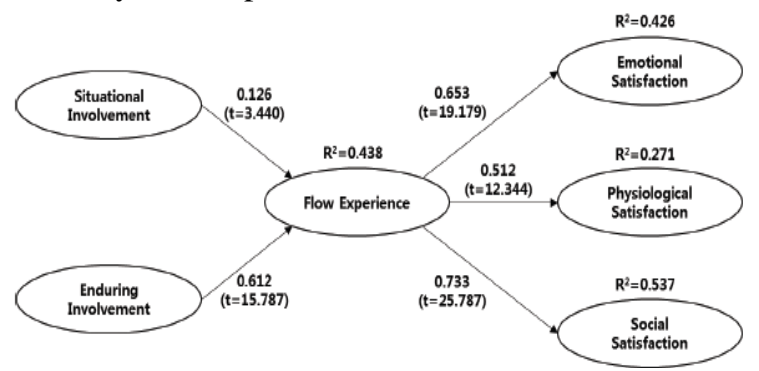

Fig. 1. Statistical significance for each path

\section{CONCLUSION}

This research has attempted to find how 'flow experience' plays role between leisure involvement and leisure satisfaction. To achieve this purpose, we analyzed 390 questionnaires got from university students. In summary, this paper has three main findings.

First, we found that leisure involvement has a positive impact on flow experience. Second, leisure satisfaction was divided by emotional satisfaction, physiological satisfaction, social satisfaction. Finally, we find the effects of leisure involvement on satisfaction were mediated by flow experience.

In conclusion, we provide managerial implications to various area through this research. But, the present paper was limited in respondents. Further studies on different largescale assessments are needed.

\section{REFERENCES}

1. Dumazedier, J., Leisure and the social system. In Concepts of leisure, J. F. Murphy ed. (1974), Englewood Cliffs, NJ, Prentice-Hall.

2. Kelly, J. R., Work and leisure: a Simplified paradigm. Journal of Leisure Research, $4.1 \quad$ (1972) 50-62.http://doi/org/10/1080/00222216.1972.11970057

3. Beard, J. G., and Ragheb, M. G., Measuring leisure satisfaction. Journal of leisure Research, 12.1 (1980), 20-33.

4. Beard, J. G., and Ragheb, M. G., Measuring leisure attitude. Journal of $\begin{array}{llll}\text { leisure } & \text { Research, } & 14.2 \quad \text { (1982), } & \text { 155-168 }\end{array}$ http://doi.org/10.1080/00222216.1982.11969512

5. Iso-Ahola, S. E., Toward a Social psychological theory of tourism motivation: A rejoinder. Annals of Tourism Research, 9.2 (1982), 256-262.https://doi.org/10.1016/0160-7383(82)90049-4
6. Iso-Ahola, S. E., and Weissinger, E., Perceptions of boredom inleisure: Conceptualization, reliability and validity of the leisureboredom scale. Journal of Leisure Research, $22.1 \quad$ (1990) 1-18.https://doi.org/10.1080/00222216.1990.11969811

7. Kepferer, J., and Laurent, G., Consumer involvement profiles: Anewpractical approach to consumer involvement. Journal of Advertising Research, $25.6 \quad$ (1985), 48-56.https://EconPapers.repec.org/RePEc:hal:journl:hal-00786782

8. Zaichkowsky, J. L., Measuring the involvement construct. Journal of Consumer Research, $12.3 \quad$ (1985), 341-352.https://doi.org/10.1086/208520

9. McIntyre, N., and Pigram, J. J., Recreation specializationreexamined: The case of vehicle-based campers. Leisure Sciences, 14.1 (1992), 3-15.https://doi.org/10.1080/01490409209513153

10. Cheng, T. M., and Tsaur, S. H., The relationship between serious leisure characteristics and recreation involvement: A case of study of Taiwan's surfing activities. Leisure Studies, $31.1 \quad$ (2012), 53-68.https://doi.org/10.1080/02614367.2011.568066

11. Kyle, G. T., and Chick, G. E., Enduring leisure involvement: The importance of personal relationships. Leisure Studies, 23.3 (2004), 243-266.https://doi.org/10.1080/0261436042000251996

12. Mactavish, J., and Schleien, S., Patterns of family recreation in families that include children with a developmental disability. Journal of Leisure Research 29.1

(1997), 21-47.https://doi.org/10.1080/00222216.1997.11949781

13. Randall, E. T., and Bohnert, A. M., Organized activity involvement, depressive symptoms, and social adjustment in adolescents: Ethnicity and socioeconomic status as moderators. Journal of Youth and Adolescence, 38.9 1187-1198. https://doi.org/10.1007/s10964-009-9417-9

(2009),

14. Chen, Y. C., Li, R. H., and Chen, S. H., Relationships among adolescents' leisure motivation, leisure involvement, and leisure satisfaction: a structural equation model. Social Indicator Research, 110.3 (2013),

1187-1199. https://doi.org/10.1007/s11205-011-9979-2

15. Havitz, M. E., and Mannell, R. C., Enduring involvement, situational involvement, and flow in leisure and non-leisure activities. Journal of Leisure Research, $37.2 \quad$ (2005), 152-177.https://doi.org/10.1080/00222216.2005.11950048

16. Havitz, M. E., and Dimanche, F., Leisure involvement revisited: Drive properties and paradoxes. Journal of Leisure Research, 31.2 (1999), 122-150. https://doi.org/10.1080/00222216.1999.11949854

17. Rothschild, M., Perspectives on involvement: Current problems and future directions. Advances in Consumer Research, 11 (1984), 216-217.http://acrwebsite.org/volumes/6245/volumes/v11/NA-11

18. Richins, M. L., and Bloch, P. H., After the new wears off: The temporal context of product involvement. Journal of Consumer Research, 13 (1986), 280-185.https://doi.org/10.1086/209067

19. Csikszentmihalyi, M., Play and intrinsic rewards. Journal of Humanistic Psychology, 15.3 (1975), 41-63.

20. Nakamura, J., and Csikszentmihalyi, M., Flow theory and research Handbook of positive psychology (2009), 195-206.

21. Engeser, S., and Rheinberg, F., Flow, performance and moderators of challenge-skill balance. Motivation and Emotion, 32.3 (2008), 158-172.10.1007/s11031-008-9102-4

22. Csikszentmihalyi, M., and Hunter, J., Happiness in everyday life: The uses of experience sampling. Journal of Happiness Studies, 4.2 (2003), 185-199. https://doi.org/10.1023/A:1024409732742

23. Wu, H. J., and Liang, R. D., The relationship between whit-water rafting experience formation and customer reaction: A flow theory perspective. Tourism management, $32.2 \quad$ (2011), $317-325$ https://doi.org/10.1016/j.tourman.2010.03.001

24. Heo, J., Lee, Y., McCormick, B. P., and Pedersen, P. M., Daily experience of serious leisure, flow and subjective well-being of older adults. Leisure $\quad$ Studies, $29.2 \quad$ (2010), 207-225.https://doi.org/10.1080/02614360903434092

25. Jackson, S. A., Thomas, P., Marsh, H. W., and Smethurst, C.,Relationships between flow, self-concept, psychological skills andperformance. Journal of Applied Sport Psychology, 13 (2001), 129-153.https://doi.org/10.1080/104132001753149865

26. Jackson, S. A., and Marsh, H. W., Flow scale test manual (2002), St Lucia, Queensland: Fitness Information Technology Publishers.

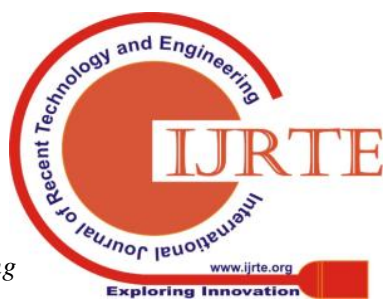


27. Jackson, S. A., Martin, A. J., and Eklund, R. C., Long and Short measures of flow: The construct validity of the FSS-s, DFS-2 and new brief counterparts. Journal of Sport \& Exercise Psychology, 30 (2008), 561-587.https://doi.org/10.1123/jsep.30.5.561

28. Jackson, S. A., Factor influencing the occurrence of flow state in elite athletes. Journal of Applied Sport Psychology, 7.2 (1995), 138-166.https://doi.org/10.1080/10413209508406962

\section{AUTHORS PROFILE}

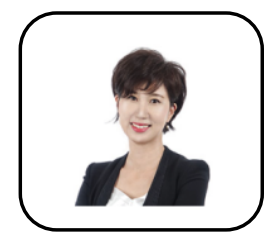

HeeJung Leeis an Associate Professor in Department of Business Administration, CHA University. She received her Ph.D. in Tourism, Leisure, Hotel, and Sport Management from Griffith University, Australia. The topics of her previous publications include social media contents, mobile usages, and travel motivations. Recently, she focuses on increasing customer happiness in various service industry byutilizing new technologies.

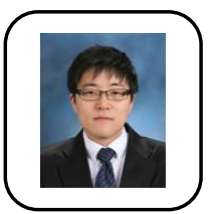

Janghyun Kim is an Assistant professor in the Department of Business Administration, Kunsan National University, Korea. His research interests include arts marketing, customer satisfaction, SNS marketing, and Korean wave, etc. He received the Best Paper Award in Korea Marketing Research and Journal of Cultural Industry Studies. His studies are published in several journals such as International Journal of Advertising, Korean Management Review, Korea Marketing Review, Journal of Distribution Science, Information-an International Interdisciplinary Journal, and Indian Journal of Science \& Technology.

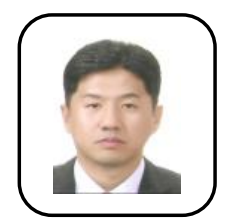

Ilhyun Baeis a Professor in the College of Business Administration, Hyupsung University, Korea. His research interests include service marketing, culture marketing, distribution management, logistics and Korean wave, etc. He received 2016 Best Paper Award from Korea Ministry of Land, Infrastructure and Transport. And he also received 2013 Best Paper Award from Korea Society of Cultural Industry. His studies are published in several journals such as Korean Management Review, Korea Marketing Review, Korea Distribution Management Review, Korea Logistics Review and Information-an International Interdisciplinary Journal. 